\title{
LIBYAN STUDIES
}

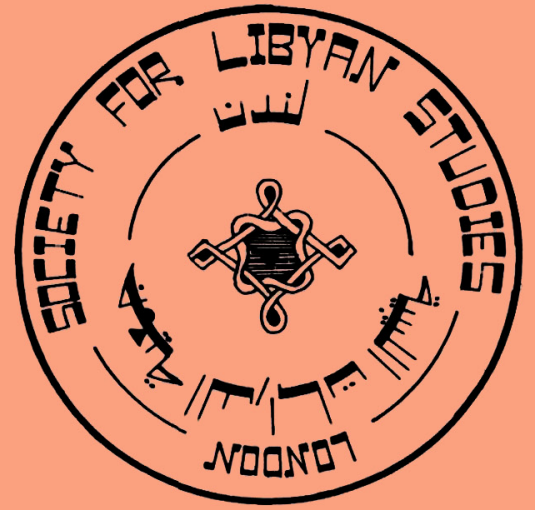

\section{Twelfth Annual Report of the Society for Libyan Studies (1980-81)}

\author{
c/o The Institute of Archaeology \\ 31-34 Gordon Square \\ London WC1H OPY
}




\section{LIBYAN STUDIES}

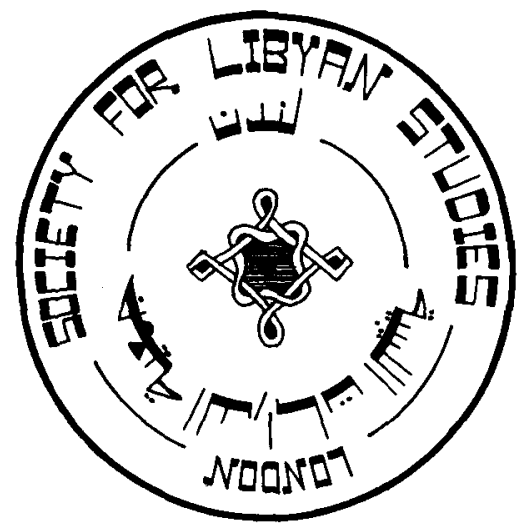

\section{Twelfth Annual Report of the Society for Libyan Studies (1980-81)}

c/o The Institute of Archaeology

31-34 Gordon Square

London WC1H OPY 


\section{CONTENTS}

PAGE

Annual Report ..$\quad$. $\quad . \quad$. . . . . . . . . . . 5

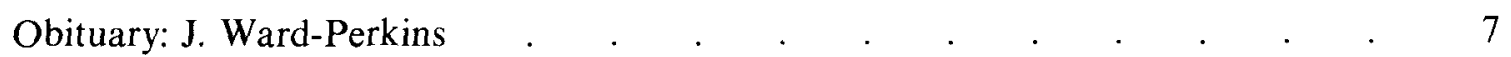

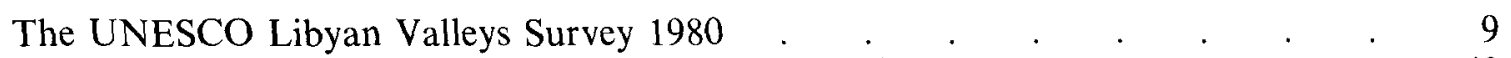

Three Soldiers of the Cohors Hispanorum in Cyrenaica . . . . . . . . 49

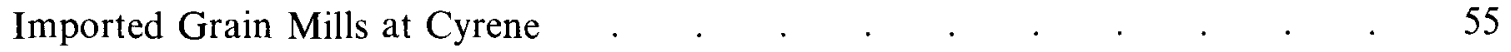

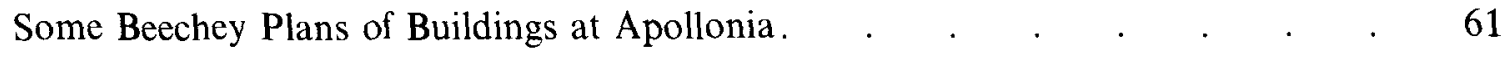

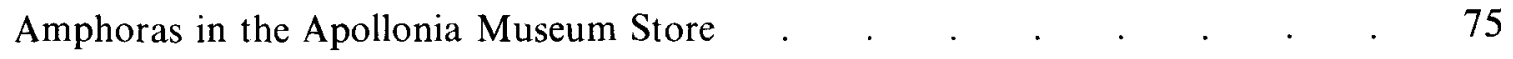

Monitoring Land and Water Use in the Gefara Region by Satellite Imagery . 79

The Libyan Valleys Project Seminar. . . . . . . . . . . 81

The Economic and Social Development of Libya in the Late Nineteenth and the

Twentieth Centuries . . . . . . . . . . . . . . . . . 83

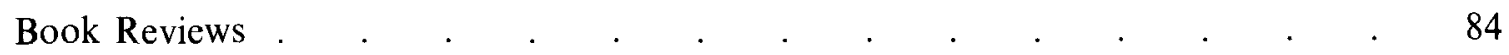

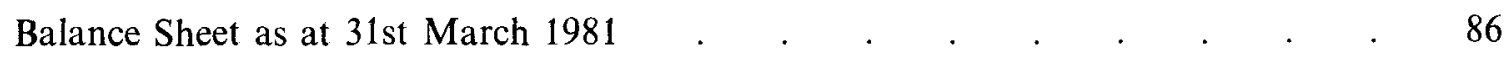

Income and Expenditure Account for the year ended 31st March 1981 . . . $\quad$. 87

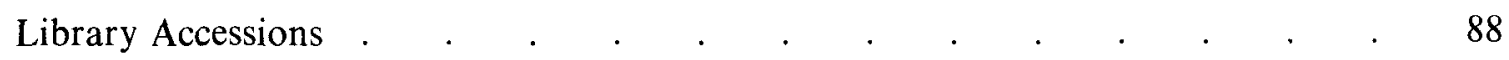

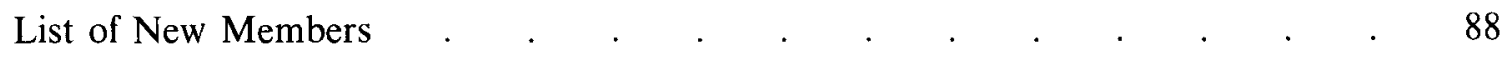

